\title{
ACOLHIMENTO INSTITUCIONAL, JUDICIALIZAÇÃO DE DIREITOS E A CONVIVÊNCIA FAMILIAR E COMUNITÁRIA
}

\author{
Andréa Márcia Santiago Lohmeyer Fuchs, Nathalia Coppini, Gisela Júlia Moraes Willwock \\ Universidade Federal de Santa Catarina - UFSC. E-mail: nathicoppini@hotmail.comn
}

\section{RESUMO}

O artigo objetiva discutir a judicialização de direitos violados de crianças e adolescentes, tendo os processos de Acolhimento Institucional como objeto de estudo. Para tanto, foi realizada uma pesquisa documental que selecionou 32 processos judiciais. A coleta dos dados considerou três documentos: o ofício ou relatório do Conselho Tutelar, a manifestação do Ministério Público e a Guia de Acolhimento judicial. A interpretação e análise dos dados qualitativos baseou-se na técnica da Análise de Conteúdo. Os resultados da pesquisa sugerem que o fator violação/negligência (familiar) é indicado expressivamente como motivação para o acolhimento institucional, e que as medidas aplicadas pelo sistema de justiça aos pais ou responsáveis se expressam em raras articulações entre as políticas públicas de proteção social. Ademais, os dados sugerem que o Sistema de Garantia de Direitos não tem priorizado o direito à convivência familiar e comunitária, o que revitimiza crianças e adolescentes e viola princípios infraconstitucionais: primeiro, pela institucionalização e, segundo, pela suspensão de visitas de pais, responsáveis e/ou membros da família extensa, rompendo vínculos familiares. Conclui-se que, muito embora a convivência familiar e comunitária seja um direito fundamental de crianças e adolescentes, este não tem sido totalmente cumprido pelos operadores do Sistema e Garantia de Direitos quando optam como primeira resposta pública o acolhimento institucional, inculpando exclusivamente a família pela não garantia de direitos e, sobretudo, levando, de maneira indiscriminada, ao afastamento da família de origem em casos que seguramente demandariam um trabalho social de restabelecimento de vínculos.

Palavras-chave: Criança e adolescente. Judicialização de direitos. Acolhimento Institucional. Negligência.

\section{INSTITUTIONAL FOSTER CARING, JUDICIALIZATION OF RIGHTS AND FAMILY AND COMMUNITY COEXISTENCE}

\begin{abstract}
The article aims to discuss the judicialization of violated rights of children and adolescents, having the Institutional Foster Care processes as the object of study. This research, conducted in 2021, analyzed documents from 32 judicial proceedings. The selective steps considered the existence of a petition filed by the Guardianship Council, a statement by the Public Prosecution and the Judicial Foster Care Form. The interpretation and analysis of the collected qualitative data was based on the Content Analysis technique. The research results suggest, among others, that the violation factor (family neglect) is expressively indicated as a motivation for institutional foster care, and that the measures applied by the justice system to parents or guardians are expressed in rare articulations between public policies for social protection. Furthermore, the data suggest that the Rights Guarantee System has not prioritized the right to family and community coexistence, which re-victimizes children and adolescents and violates infra-constitutional principles, first by institutionalization them and second by the suspending visits from parents, guardians and/or extended family members, thus breaking family ties.
\end{abstract}

Keywords: Child and Adolescent. Judicialization of rights. Institutional Foster Care. Negligence. 


\section{INTRODUÇÃO}

Historicamente a resposta dada pelo Estado às crianças e adolescentes provenientes de famílias pobres, periféricas e vulneráveis foi o confinamento em instituições totais (RIZZINI, 2004; 2006). Em sentido oposto, o Estatuto da Criança e Adolescente (BRASIL, 1990) e posteriormente a Lei 12.010/2009 (BRASIL, 2009) estabeleceram a convivência familiar e comunitária de crianças e adolescentes como um dos direitos humanos fundamentais. Nesse sentido, a ausência e/ou precarização das condições objetivas das famílias não constitui fundamento legal para a retirada de crianças e adolescentes do ambiente familiar, devendo obrigatoriamente serem incluídas em programas e serviços oficiais de políticas públicas, em especial, as sociais (COSTA, 1995; FALEIROS, 2011).

Nessa perspectiva, o Acolhimento Institucional deve ser uma medida protetiva adotada em favor da criança e do adolescente quando todas as alternativas para se manter a criança ou o adolescente na família se esgotarem. Quando da necessidade de institucionalização, os princípios de excepcionalidade e brevidade são fundamentais para a organização e gestão do atendimento de crianças e adolescentes acolhidos nas instituições por determinação judicial.

A intervenção em crianças e adolescentes com direitos violados exige, assim, a ação de diferentes atores político-sociais na efetivação de atendimento à criança e ao adolescente, igualmente articulados e responsabilizados "tanto na compreensão das dificuldades e problemas existentes quanto na construção de alternativas de enfrentamento e busca de soluções que favoreçam a população infanto-juvenil, seja no âmbito coletivo ou individual" (AMORIM, 2017, p. 51); sendo essa ação articulada reconhecida pelo Sistema de Garantia de Direitos (BRASIL, 2006b; DIGIÁCOMO, 2013).

Passados mais de 30 anos de vigência da Doutrina da Proteção Integral (ECA/1990), ainda flertamos com a Doutrina da Situação Irregular (BRASIL, 1979), ${ }^{1}$ que considerava crianças,

\footnotetext{
${ }^{1}$ A Doutrina da Situação Irregular, fundamentava o Código de Menores - Lei 6.667, de 10 de outubro de 1979 -e direcionava suas ações judicializadas, normalmente como prioritárias, apenas para quatro categorias de "menores": os carentes, os abandonados, os inadaptados e os infratores.
}

adolescentes e suas famílias como responsáveis pela sua condição de vulnerabilidade e/ou violação de direitos e os tratava como objetos de intervenção social (VERONESE; COSTA, 2006).

Este artigo pretende discutir, a partir dos resultados da pesquisa realizada entre 2019 e 2021, a judicialização de direitos violados de crianças e adolescentes, por meio da aplicação de medida de Acolhimento Institucional, e seu rebatimento no direito à convivência familiar e comunitária.

\section{MÉTODOS}

As bases metodológicas norteadoras se fundamentaram na pesquisa quantiqualitativa. Entende-se que a quantidade indica o horizonte da extensão, e a qualidade representa a intensidade das coisas, pois não há dicotomia entre qualidade e quantidade. Toda qualidade também deixa rastros quantitativos. É próprio da dialética não reduzir um termo ao outro, mas manter entre eles relacionamento polarizado tipicamente não linear (DEMO, 1981; 2000). A ideia de pesquisa qualitativa conduz ao conceito de intensidade em contraposição dialética ao de extensão. Contudo, nessa contraposição dialética, está implícito que intensidade e extensão ou qualidade e quantidade não são categorias antagônicas, mas essenciais (DEMO, 2000; 2001).

Assim, inicialmente, na etapa quantitativa, realizou-se em 2019 um levantamento que mapeou 219 crianças e adolescentes, que foram acolhidos institucionalmente, como medida protetiva, entre os anos de 2016 e 2019, em 10 Instituições de Acolhimento de crianças e adolescentes no município de Florianópolis (SC).

Posteriormente, em 2020 e 2021, na etapa qualitativa, ocupou-se da coleta e análise documental em processos judiciais de crianças e adolescentes com direitos violados; aprofundando, por meio da análise qualitativa, as motivações do Acolhimento Institucional dessas crianças e adolescentes, envolvendo os principais atores do Sistema de Garantia de Direitos, sendo eles o Conselho Tutelar, o Ministério Público e a Vara da Infância e Juventude.

A coleta e a análise estratégica - a qual se considera "aquela que se fundamenta nas teorias das ciências sociais, mas tem como principal objetivo esclarecer determinados aspectos da realidade para a ação das políticas 
públicas" (MINAYO, 1991, p. 236) - foi referenciada na técnica da Análise de Conteúdo (BARDIN, 1979).

Em vista disso, foram adotadas três etapas para a análise dos dados: a pré-análise, que consiste na leitura do material e retorno aos objetivos iniciais com elaboração de préindicadores; a exploração do material ou codificação, que consiste em categorizar o conteúdo, definir quantitativos organizativos e classificação dos dados e, por último, o tratamento dos resultados, que propõe as inferências e interpretação teórica dos achados (BARDIN, 1977). Dessa forma, a começar da expansão dos descritores, categorizados a partir da leitura minuciosa nos três documentos centrais: ofício ou relatório do Conselho Tutelar, Manifestação do Ministério Público e Guia de Acolhimento, contendo o despacho judicial, foi possível chegar aos resultados que serão parcialmente apresentados neste artigo, considerando o objetivo proposto.

O corpus da pesquisa, na etapa qualitativa, foi definido partindo de uma seleção aleatória $^{2}$ das 219 crianças e adolescentes acolhidos (entre 2016 e 2019), tendo três critérios de inclusão. Assim sendo, os processos judiciais selecionados deveriam conter: i) a documentação encaminhada pelo Conselho Tutelar ao Ministério Público (ofício ou relatório); ii) a manifestação do Ministério Público sobre representação feita pelo Conselho Tutelar e, por fim, iii) as Guias de Acolhimento expedidas após despacho judicial, sendo este 0 grande determinador do Acolhimento Institucional. Ao final chegou-se a 32 processos judiciais de crianças e adolescentes em Acolhimento Institucional no município de Florianópolis (SC).

A coleta foi realizada em 13 dias in loco na instituição do Ministério Público do Estado de Santa Catarina (MPSC), totalizando 58 horas e 32 minutos, tendo a autorização legal do Promotor de Justiça e na presença de uma funcionária durante a coleta documental. Foram catalogadas 1.380 páginas de documentos contidos nos processos.

A catalogação dos documentos processuais foi inserida em um banco de dados, a partir de descritores construídos com base nos objetivos da pesquisa e a leitura minuciosa dos documentos (BARDIN, 1979).

\footnotetext{
${ }^{2}$ Aplicação da fórmula "Aleatório ()" no Excel. Para versões do Excel mais antigas ou que não estejam em português, a função utilizada para a mesma seleção é "RAND ()".
}

A pesquisa foi submetida e aprovada no Comitê de Ética em Pesquisa com Seres Humanos da Universidade Federal de Santa Catarina, a partir do registro no Conselho Nacional de Ética em Pesquisa (CONEP), CAAE: 81641717.1.0000.0121 (CEPSH/UFSC), conforme determina a Resolução 510/2016.

\section{RESULTADOS}

O Conselho Tutelar (CT) tem função estratégica, pois é órgão democrático, ${ }^{3}$ dentro do Sistema de Garantia de Direitos (SGD), que tem a responsabilidade de zelar pelos direitos da criança e do adolescente. Entre suas atribuições, conforme já mencionado, compete "encaminhar ao Ministério Público notícia de fato que constitua infração administrativa ou penal contra os direitos da criança e do adolescente" (Art. 13, inciso IV apud BRASIL, 2019).

Contudo, em muitas situações, o Conselho Tutelar solicita a medida protetiva de Acolhimento Institucional de crianças e adolescentes que se encontram com suspeita de violação de direitos, pelas mais variadas justificativas. Segundo D'Ornellas (2017) ao acolher uma criança, mesmo que emergencialmente, conforme prevê o ECA, promove-se a judicialização de uma situação em que a resposta pública poderia ser dada sem intervenção do Poder Judiciário. Acolher é a melhor resposta de caráter protetivo? Sabemos que o Conselho Tutelar, por Lei, ao optar pelo Acolhimento Institucional emergencial, deve comunicar o fato ao juiz em 24 horas. Contudo, como medir o tempo entre a proteção e a revitimização? Essas 24 horas podem vir a se transformar em 96 horas $^{4}$ e, ainda assim, estarem legalmente dentro do prazo.

Os princípios do ECA e da Lei 12.010/2009 sinalizam que, para aplicação de medidas protetivas, ${ }^{5}$ deve-se sempre fundamentar no "melhor interesse da criança". E em caso de institucionalização, devem-se esgotar as possibilidades de intervenção com família de

\footnotetext{
${ }^{3}$ Os conselheiros tutelares são membros da comunidade escolhidos por processo eleitoral unificado (BRASIL, 2019). Podem participar todas as pessoas da comunidade local maiores de 21 anos, que possuam domicílio eleitoral no município e que preencham as exigências previstas no ECA (Lei $8.069 / 1990$ ) e na lei municipal de criação do Conselho Tutelar.

${ }^{4}$ Se uma criança é acolhida, por exemplo, em uma quinta-feira, após fechados os trabalhos no sistema de justiça, em tese, essa criança poderá ficar legalmente em acolhimento sem notificação ao Juiz até segunda-feira.

${ }^{5}$ Aplicam-se também às medidas socioeducativas, mas que não é o caso deste artigo.
} 
origem e a rede de proteção social. Esses dois princípios garantistas trazidos na Doutrina da Proteção Integral têm sido aplicados em crianças e adolescentes pobres como fundamento legal. Contudo, em muitas dessas situações, as respostas públicas do Estado, por meio de suas instituições, têm negligenciado seu papel protetivo com as famílias, pois, em razão da estrutura social capitalista, pautada na desigualdade social, têm afetado diretamente muitas famílias, que acabam não conseguindo exercer sua função protetiva. Quando isso acontece, as políticas públicas sociais, que possuem caráter preventivo de proteção social, precisam acolher publicamente essas demandas familiares, contribuindo assim no restabelecimento da sua função protetiva, tendo em vista ser a família a placenta social no desenvolvimento humano, físico, social, psíquico de todas as crianças e adolescentes (FERRARI; VECINA, 2002).

Os resultados da pesquisa sugerem aspectos importantes da realidade analisada documentalmente. Muito embora a pesquisa qualitativa não tenha em sua finalidade a generalização dos seus achados (DEMO, 2001), os dados qualitativos a serem apresentados trazem para a cena pública e política o problema social que, por vezes, é mascarado e/ou ocultado da realidade social, com contornos referentes a faces mais profundas, nem sempre evidenciadas em uma decisão judicial que se inicia pelo órgão de proteção, mesmo que fundamentada no melhor interesse da criança e do adolescente.

\subsection{Judicialização da violação de direitos e negligência: a culpa é de quem?}

Na Política Nacional de Assistência Social (PNAS apud BRASIL, 2005), os níveis de Proteção Social que constam na Norma Operacional Básica do Sistema Único de Assistência Social (NOB/SUAS apud BRASIL, 2008) se encontram organizados entre básica, média e alta complexidades. No espaço referente à alta complexidade, na Proteção Social Especial, está situado o Serviço de Acolhimento Institucional. Além disso, o ECA (Art. $4^{\circ}$ ) e posteriormente a Lei 12.010/2009 fundamentam a decisão de institucionalização da criança ou adolescente nos princípios de excepcionalidade e brevidade, devendo ser embasada também na manutenção e garantia do direito à convivência familiar e comunitária.

Nos processos analisados, $78 \%$ dos acolhimentos institucionais foram realizados pelo Conselho Tutelar em caráter emergencial (Gráfico 1). Muito embora o ECA e a Lei 12.010/2009 assegurem a possibilidade de 0 Conselho Tutelar realizar o acolhimento em caráter emergencial, estes o fazem restringindose a situações específicas, o que não ocorreu na maioria dos processos analisados.

Figura 1. Origem do pedido de Acolhimento Institucional

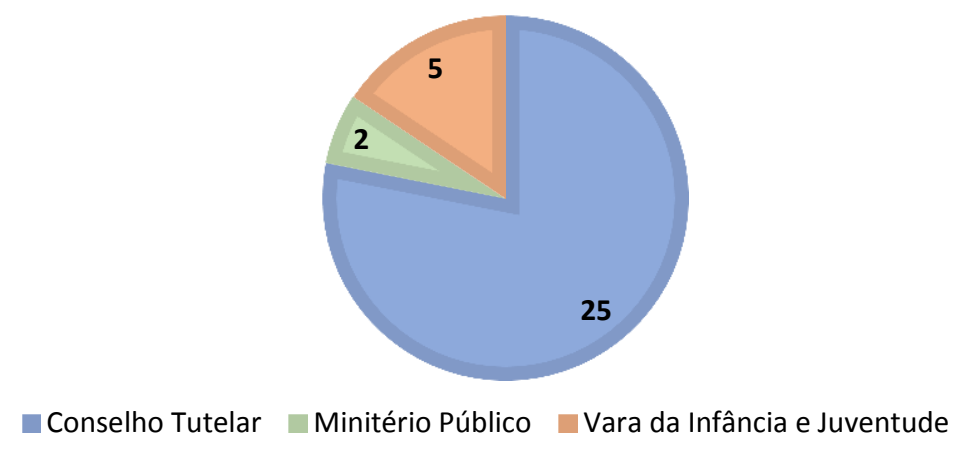

Fonte: Fuchs e Coppini (2021).

Do total de processos analisados (32), 31 das manifestações do MP e despachos do Juiz foram pela manutenção do Acolhimento Institucional, realizado de forma emergencial pelo Conselho Tutelar. Apenas em um processo o juiz determinou o desacolhimento.
Em relação às informações prestadas nos documentos do Conselho Tutelar encaminhados à Vara da Infância e Juventude (VIJ), 24 (75\%) dos processos analisados não mencionaram contato com as Unidades Básicas de Saúde (conhecidas popularmente como Posto de 
Saúde); 28 (87,5\%) não mencionaram contato com o Ministério Público; 25 (78\%) não mencionaram contato com a Polícia Militar, e apenas 11 (34,3\%) mencionaram contato com os serviços da Política de Assistência Social, e destes, apenas 2 (11\%), com serviços da Proteção Social Básica (CRAS e SCFV).

Considerando que a maioria dos casos de violação de direitos tinham como fator violação de direitos à negligência (Tabela 1), os dados sugerem que o $\mathrm{CT}$, nos processos analisados pautou-se por julgamentos morais e com base na situação imediata apresentada, trazendo assim prejuízos para sua ação institucional, que deveria estar fundamentada em bases éticas e técnicas conforme preveem os marcos normativos e regulatórios da área dos direitos da criança e do adolescente.

A partir da análise dos relatos do Conselho Tutelar nos processos analisados, ao descrever o contexto da violação de direitos que motivou o acolhimento institucional emergencial, é possível identificar a desarticulação das instituições que integram o Sistema de Garantia de Direitos nos municípios. Em um dos casos, houve uma decisão autocrática da Juíza de Alecrim, ${ }^{6}$ que não respeitou a decisão da assistência social do município que realizava o acompanhamento da família (avó e irmã), somado a isso o desrespeito à criança ao mentir para trazê-la para outra cidade com a mãe, com a qual não tinha referência afetiva (Caso LNM134). Contudo, a fundamentação do Ministério Público, homologada no Despacho Judicial, justificou a medida protetiva extrema pela "negligência da mãe", ao declarar que "foram esgotadas as possiblidades de intervenção junto à rede de proteção social" (Caso LNM134). Como consta:

Relato do Conselho Tutelar (Ofício) - [...] A criança estava acolhida na cidade de Alecrim e veio a ser desacolhida e entregue a Genitora contra a sua vontade [...]. Por essa razão, na tarde do referido dia, enquanto a Genitora levava a criança consigo ao fórum desta capital, Cravo saiu correndo do terminal de ônibus [...]. Foi necessário intervenção da polícia para resgatar a criança. [...] a criança informou que o motivo da fuga se deu porque não deseja conviver com a genitora (a quem não a reconhece como mãe). A criança afirmou que veio para Erva-Doce contra a sua vontade e assegura que foi enganado pelo Conselho Tutelar de Alecrim, pois, Ihe disseram que apenas iam visitar a sua irmã [...]. A criança sempre fora cuidada pela avó materna na cidade de Alecrim. [...] Importante também destacar que a criança expressa que foi enganada no processo de transferência. "O Cravo informou que duas conselheiras tutelares falaram para ele vir passear acompanhando a irmã Violeta, que viria para a casa da genitora e retornaria com elas, porém, ao chegar, o deixaram com mãe e foram embora, e ele se nega a ficar com ela [...].

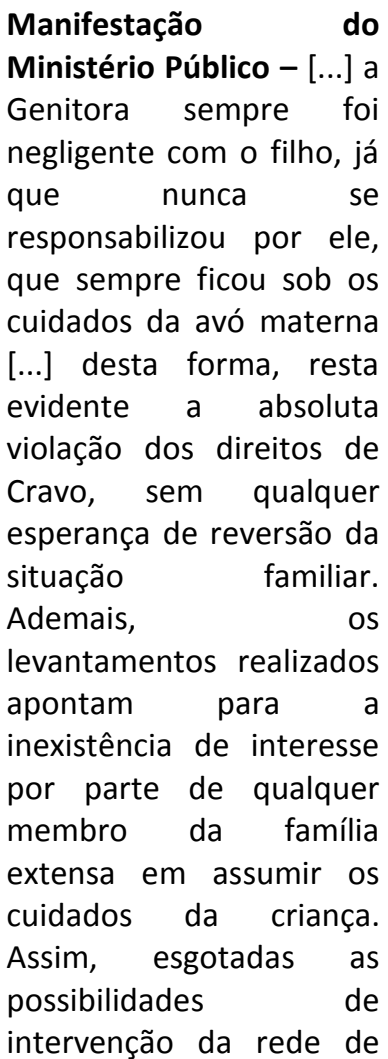

\footnotetext{
${ }^{6}$ Nomes das cidades e das crianças fictícios.
} 
proteção, não se vislumbra melhor medida do que a Destituição do poder Familiar e a manutenção do acolhimento institucional (Caso LNM134, Fls 1-5).

Em outro registro do Conselho Tutelar, no processo (Caso LRF74), a descrição da reação "desesperada" de uma mãe, quando da chegada do Conselho Tutelar, após denúncia anônima, para a retirada da criança do convívio familiar, expressa a ausência de suporte do SGD para que a família cumpra sua função protetiva. Segue o relato:

Relato do Conselho Tutelar (ofício): “No dia 08 de agosto de 2018, recebemos denúncia de que a Genitora havia sido despejada da casa onde reside com duas crianças, uma de 2 anos e outra de 7 anos e que a Genitora estava sob efeito de drogas e álcool." [...] Chegando ao local, os moradores informaram que a Genitora estava no terreno baldio ao lado da residência, mais precisamente dentro do mato, com as crianças e que possivelmente estava fazendo o uso de substâncias psicoativas... A criança de 2 anos estava de pés descalços, somente com uma camiseta e calca curta, com a fralda caindo, pois estava "cheia"; a criança de 7 anos usava apenas camisa regata, calça e chinelos, com muito frio e assustada [...] Primeiramente a Genitora não queria conversar, afirmando aos gritos que "ninguém me ajuda [...]. Queria evadir-se do locar puxando as crianças pelo braço [...]; informamos que ela teria que colaborar e não assustar as crianças. A mesma negou, continuou com voz alterada, então informamos que seria necessário ajuda da PM" [...].

Despacho judicial: Assim, esgotadas as possibilidades de intervenção da rede de proteção, não se vislumbra melhor medida do que a Destituição do Poder Familiar e a manutenção do acolhimento institucional. [...] são vítimas de negligência perpetrada por sua Genitora, a qual não realiza os cuidados de higiene e educação necessários, bem como é usuária de drogas e bebida alcoólica. Assim, se é certo que a falta de recursos materiais não constitui motivo bastante para a decretação da perda do poder familiar, não menos correta é a conclusão de que a negativa em prestar os cuidados necessários aos filhos incapazes, relegando o exercício da paternidade a terceiros e acarretando aos infantes grave situação de vulnerabilidade, constitui, sim, motivo mais do que suficiente para tanto" (Caso LRF74, fl.14).

Importante destacar que as crianças e os adolescentes também fazem suas interpretações sobre situações de violação de direitos da qual sofrem diretamente as consequências. $O$ desenho realizado por um estudante da $5^{\mathrm{a}}$ série do ensino fundamental público revela claramente sua percepção de que as condições objetivas da família afetam seus direitos. 
Figura 2. Representação da violação do direito em relação às condições dignas de sobrevivência

Fonte: COSTA, 2020 (autor: estudante da 5ạ série).

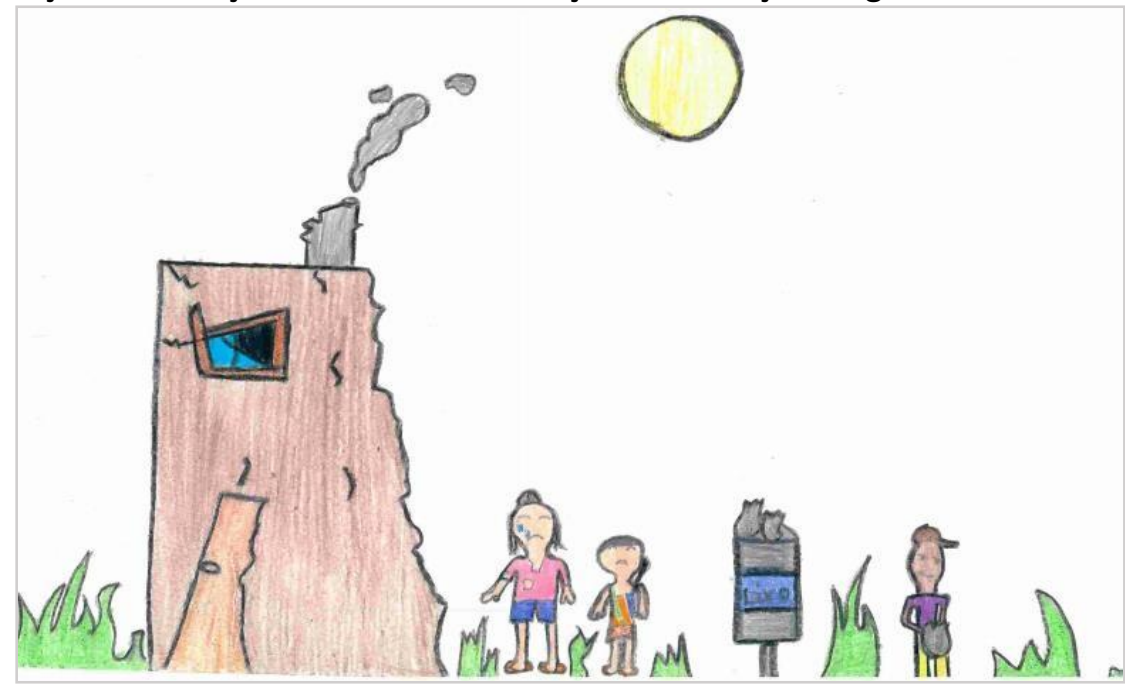

Em relação às informações descritas pelo Conselho Tutelar ao Sistema de Justiça, em 19 $(59,4 \%)$ dos processos analisados, o Ministério Público (MP) utilizou integralmente as informações prestadas no ofício do Conselho Tutelar e, em 15 (79\%) desses processos, o MP não trouxe informações complementares do Sistema de Garantia de Direitos, ou seja, independentemente do volume de informações oferecidas pelo Conselho Tutelar, o MP não foi buscar informações complementares, sobretudo por se tratar de acolhimento emergencial. Somado a isso, em 31 (97\%) das Guias de Acolhimento judicial, as quais contêm o despacho judicial, o "parecer da equipe técnica" estava na situação de desenvolvimento".

O fator violação da negligência não aparece em $50 \%$ dos ofícios que constam nos registros do Conselho Tutelar encaminhados ao Sistema de Justiça (MP e VIJ). Ou seja, o Conselho Tutelar decide pelo acolhimento, informa ao promotor e juiz com um ofício com média de três páginas, e o fator violação é tipificado/qualificado pelo Ministério Público e Vara da Infância e Juventude. "[...] são vítimas de negligência perpetrada por sua genitora, a qual não realiza os cuidados de higiene e educação necessários [...], é usuária de drogas e bebida alcoólica" (LRF74, fl. 114). ${ }^{7}$ Este relato é validado pelo Ministério Público e pela Vara da Infância, que acatam, por vezes, sem contestação, culminando no Acolhimento Institucional.
Somente $15,6 \%$ do total dos processos analisados (32), acusaram violência e/ou violência sexual - hipótese que o Conselho Tutelar tem de aplicação de medida legitimada por lei (Tabela 1).

A primeira ressalva, estatuída no art. 136, inc. I, do Estatuto, é a possibilidade de o Conselho Tutelar, ao atender crianças e adolescentes, aplicar as medidas previstas no art. 101, I a VII, incluindo, portanto, o acolhimento institucional, embora apenas nas hipóteses do art. $101 \S 2$, ou seja, em casos de violência ou violência sexual (BAPTISTA, 2010, p. 396).

\footnotetext{
${ }^{7}$ Informações extraídas de um processo analisado referente à manifestação do MP sobre o Acolhimento Emergencial, no qual foi mantida a decisão tomada pelo Conselho Tutelar.
} 
Tabela 1. Fator violação de direitos, segundo incidência e origem do Conselho Tutelar

\begin{tabular}{cccccc}
\hline Fator violação & Centro & $\begin{array}{c}\text { Continent } \\
\text { e }\end{array}$ & Norte & Sul & $\begin{array}{c}\text { Total } \\
\text { Geral }\end{array}$ \\
\hline Não menciona & 7 & 3 & 5 & 1 & $\mathbf{1 6}$ \\
\hline Negligência & 2 & 1 & 5 & 1 & 9 \\
\hline $\begin{array}{c}\text { Negligência e violência física; } \\
\text { negligência na gestação e situação } \\
\text { de rua }\end{array}$ & 2 & 1 & & & 3 \\
\hline Trabalho infantil & & & & & 1 \\
\hline Violência física, sexual e intrafamiliar & & 1 & 2 & & 3 \\
\hline Total Geral & $\mathbf{1 1}$ & $\mathbf{6}$ & $\mathbf{1 3}$ & $\mathbf{2}$ & $\mathbf{3 2}$ \\
\hline
\end{tabular}

Fonte: Pesquisa (FUCHS; COPPINI, 2021). Elaboração própria.

No âmbito da Saúde Pública, a negligência é um problema de violência interpessoal posicionada entre as tipologias de violência física, sexual e psicológica. Segundo dados do DISQUE 100 (BRASIL, 2019), entre 2011 e 2019 foram registradas 1.549.116 denúncias de violência física, sexual, psicológica e negligência. Desse total, $38 \%$ eram de negligência; $25,6 \%$, violência psicológica; $23 \%$, violência física e $13,4 \%$, violência sexual.

Tabela 2. Dados DISQUE 100

\begin{tabular}{ccccc}
\hline ANO & $\begin{array}{c}\text { VIOLÊNCIA } \\
\text { FÍSICA }\end{array}$ & $\begin{array}{c}\text { VIOLÊNCIA } \\
\text { SEXUAL }\end{array}$ & $\begin{array}{c}\text { VIOLÊNCIA } \\
\text { PSICOLÓGICA }\end{array}$ & NEGLIGÊNCIA \\
\hline 2011 & 41800 & 28525 & 36536 & 51772 \\
\hline 2012 & 60397 & 37726 & 63858 & 88750 \\
\hline 2013 & 52890 & 31895 & 62538 & 91159 \\
\hline 2014 & 39164 & 22840 & 44752 & 67831 \\
\hline 2015 & 34119 & 17583 & 36794 & 58567 \\
\hline 2016 & 32040 & 15707 & 33860 & 54304 \\
\hline 2017 & 33105 & 20330 & 39561 & 61416 \\
\hline 2018 & 30962 & 17073 & 37160 & 55375 \\
\hline 2019 & 33374 & 17029 & 36304 & 62020 \\
\hline Total Geral & $\mathbf{3 5 7 8 5 1}$ & $\mathbf{2 0 8 7 0 8}$ & $\mathbf{3 9 1 3 6 3}$ & $\mathbf{5 9 1 1 9 4}$ \\
\hline
\end{tabular}

Fonte: DISQUE 100 (BRASIL, 2020).

Cabe destacar que o Disque Direitos Humanos, ou Disque 100, é um canal de comunicação direta de denúncia em caso de situações de violação de direitos. As denúncias feitas são identificadas em suas regiões e encaminhadas para os órgãos de proteção dos municípios para que iniciem o processo de atendimento e acompanhamento tomando as medidas cabíveis. É certo que nem todas as denúncias se materializam efetivamente, e violações de direitos são constatadas. Mas certamente aí está a ponta do problema, quer seja pelo volume notificado, quer pela ausência de um sistema de informação integrado que registre o fato desde a violência até a situação resolvida e/ou encaminhada.

\subsection{A revitimização de crianças e adolescentes e a convivência familiar \\ O esforço perpetrado pelo ECA com a} Doutrina da Proteção Integral e pelas ações das políticas públicas na quebra de paradigmas do Código de Menores (1979) e a Doutrina da Situação Irregular demarcam um novo olhar sobre a infância. No entanto, essa quebra de paradigmas parece não ter força quando a infância e adolescência são postas na atuação estatal por meio da judicialização. 
Observa- se que, dos 32 processos analisados, a proibição da visitação aos pais, responsáveis e/ou família ampliada ocorreu em $50 \%$ (16) deles. No entanto, ao observar apenas o motivo negligência (familiar), a proibição de visitações ocorreu em $72 \%$ das ocasiões (Tabela 3).
Por fim, no que tange à medida protetiva de fortalecimento de vínculos (prerrogativa do Conselho Tutelar), os dados também sugerem que ela não passa a ser aplicada de imediato aos pais e, sim, majoritariamente requer sua manifestação ao Ministério Público (72\%).

Tabela 3. Motivo da violação de direitos, segundo a proibição da visitação

\begin{tabular}{|c|c|c|c|c|}
\hline \multirow[t]{2}{*}{ Motivo (violação) } & \multicolumn{4}{|c|}{ Proibição da visitação } \\
\hline & Sim & Não & Não coletado & Total Geral \\
\hline Conflitos no ambiente familiar & 0 & 2 & 0 & 2 \\
\hline Abusos físicos ou psicológicos e negligência & 1 & 0 & 0 & 1 \\
\hline $\begin{array}{l}\text { Pais ou responsáveis dependentes químicos ou } \\
\text { alcoolistas }\end{array}$ & 0 & 2 & 0 & 2 \\
\hline Abandono pelos pais ou responsáveis & 2 & 3 & 0 & 5 \\
\hline Negligência & 13 & 5 & 0 & 18 \\
\hline Não coletado & 0 & 0 & 4 & 4 \\
\hline Total & 16 & 12 & 4 & 32 \\
\hline
\end{tabular}

Fonte: Pesquisa (FUCHS; COPPINI, 2021). Elaboração própria.

Sobremaneira, os dados sugerem que o rompimento de vínculos se potencializa quando, além do Acolhimento Institucional da criança e/ou adolescente, ocorre a proibição de visitação para os pais, responsáveis ou membros da família ampliada (Tabela 3).

\section{DISCUSSÃO}

O Acolhimento Institucional é uma medida protetiva, prevista no ECA e é voltado a crianças e adolescentes vítimas de violação de direitos, incluindo aqueles ocorrido no contexto intrafamiliar. Muito embora seja uma medida protetiva, ao provocar o afastamento da criança ou adolescente do convívio familiar e comunitário de origem, traz impactos objetivos e subjetivos ao desenvolvimento ontológico da criança e dos adolescentes. Santos (2011) assegura que "[...] estes sujeitos não devem ser desvinculados de sua família de origem pelo fato de estarem institucionalizados" (SANTOS, 2011, p. 68).

Portanto, a medida protetiva de Acolhimento Institucional deve ser aplicada perante a impossibilidade de manutenção dos vínculos familiares, não devendo persistir por um período superior a dois anos, e sempre visando primeiramente à reintegração familiar.

Sendo assim, as ações, antes mesmo do processo de judicialização - quando o Conselho Tutelar decide pelo Acolhimento emergencial ou quando peticionado ao juiz - , tais medidas envolvem decisões técnicas e políticas que precisam assegurar prioritariamente o melhor interesse da criança e, portanto, devem ser esgotadas todas as possibilidades de manutenção da criança ou adolescente na família de origem.

Contudo, os resultados da pesquisa apresentados sugerem que há uma ação viciada $\mathrm{e}$ direcionada do Sistema de Justiça, que ainda se alimenta de práticas da antiga Doutrina da Situação Irregular, ao remeter os casos de violação de direitos, que pouco ou sequer foram acionados, às instituições do SGD para tentativas de reverter a situação de violação, inculpando as famílias, sobretudo a genitora, ao tipificar como negligência o fator violação da maioria dos processos analisados. Se a família é considerada responsável por seus membros e sentencia a criança à institucionalização, qual a responsabilização do Estado ao negligenciar as famílias no acesso aos Serviços de proteção social?

Muito embora o Conselho Tutelar seja autorizado a aplicar a medida protetiva de Acolhimento Institucional,

A primeira ressalva, estatuída no art. 136, inc. I, do Estatuto, é a possibilidade de o Conselho Tutelar ao atender crianças e 
adolescentes, aplicar as medidas previstas no art. 101, I a VII, incluindo, portanto, o acolhimento institucional, embora apenas nas hipóteses do art. 101 , parágrafo $2^{\circ}$, ou seja, em casos de violência e abuso sexual (BAPTISTA, 2010, p. 396).

Contudo, ainda se percebe um gap entre o "direito real" e o "direito legal". Os dados apontados nos resultados sugerem que, não raro, o Conselho Tutelar ocupa o lugar do Sistema de Justiça, solicitando acolhimento institucional, em sua maioria, pelo fator violação da negligência.

Nos diferentes registros feitos pelo próprio Conselho Tutelar submetidos à análise neste estudo, foi possível identificar diversas situações complexas, que exigiriam, antes mesmo do acolhimento emergencial, maiores elementos para uma avaliação mais aprofundada, apoiada em elementos técnicos. No entanto, observou-se uma descrição por vezes rasa e permeada de juízo moral sobre problemas afetos à criança e adolescentes, que são, por força da lei, sujeitos de direitos e prioridade absoluta nas políticas públicas (BRASIL, 1990; 2009). Somado a isso, o Ministério Público recepciona o relato frágil e, ao inseri-lo integralmente na sua manifestação, lhe confere um status legal, visto ser o Ministério Público uma autoridade no Sistema de Justiça.

Nesse sentido, muitos argumentos (in)justificados por negligência familiar para o acolhimento institucional demonstram a precariedade da articulação com a rede socioassistencial, imprescindível para oferecer às famílias as condições pertinentes à atenção de necessidades básicas, proporcionando-lhes o efetivo exercício da função da qual são encarregadas, juntamente com o Estado e a sociedade, a saber, a proteção de suas crianças e seus adolescentes. Sendo assim,

$$
\begin{aligned}
& \text { Art. 23. A falta ou a } \\
& \text { carência de recursos } \\
& \text { materiais não constitui } \\
& \text { motivo suficiente para a } \\
& \text { perda ou a suspensão } \\
& \text { poder familiar. } \\
& \S 1^{\circ} \text { Não existindo outro } \\
& \text { motivo que por si só } \\
& \text { autorize a decretação da } \\
& \text { medida, a criança ou o } \\
& \text { adolescente será mantido }
\end{aligned}
$$

em sua família de origem, a qual deverá obrigatoriamente ser incluída em serviços e programas oficiais de proteção, apoio e promoção (BRASIL, 1990).

A decisão administrativo-organizacional do Conselho Tutelar, acolhida pelo Sistema de Justiça, para receber as comunicações de Acolhimento Institucional emergencial realizado ou pedido pelo Conselho Tutelar apenas pelo documento em formato de ofício ${ }^{8}$ e por um ofício encaminhando um relatório técnico (em apenas um dos processos, o CT havia mandado um relatório junto com o ofício, porém de outra instituição do SGD, detalhando os fatos), torna ainda mais frágeis as bases factuais, teóricas, técnicas e éticas da decisão excepcional tomada pelo Conselho Tutelar.

É certo que juízes solicitam em seus despachos a necessidade de relatório técnico em 30 dias. Mas estamos tratando de um ou mais direitos suspensos, em sua maioria de crianças, por meio da sua judicialização, que culminou em uma medida extrema com retirada da criança do ambiente familiar com suspeita de violação de direitos sobre ela.

Muito embora em todos os despachos do juiz apareça a situação: "relatório social em desenvolvimento", estamos tratando de acolhimento de crianças e adolescentes em caráter emergencial, em situações pouco esclarecidas e que os relatórios complementares têm prazo de 30 dias, conforme consta no despacho do juiz. Como dimensionar essa "régua do tempo", em menor ou maior tempo, quando estamos falando de direito violado, de medida extrema de retirada da criança e do adolescente do ambiente familiar e das consequências socioemocionais provocadas tanto pela violação de direitos sofrida quanto da institucionalização que, mesmo defendendo direitos, é uma medida que as revitimiza.

O Acolhimento Institucional, conforme já dito, está descrita na Política de Assistência Social, e está inserido na Proteção Social Especial

\footnotetext{
${ }^{8} \mathrm{O}$ ofício é um documento oficial, mas que em geral, tem função restrita de solicitar, comunicar ou notificar sobre um determinado assunto. Sua própria escolha pelo Conselho Tutelar como documento formal a ser enviado ao MP, sinaliza uma escolha técnica e política sobre uma decisão fundamental que define e impacta sobremaneira a vida de crianças e adolescentes, em sua maioria pobres e periféricos.
} 
de Alta Complexidade, justamente por dispor do rompimento parcial ou total de vínculos familiares e/ou comunitários (BRASIL, 2005). A família, uma instituição privada, quando apresenta expressões da questão social, ${ }^{9}$ principalmente, em face das violências, passa a se tornar objeto da intervenção pública (RODRIGUES; PEREIRA, 2012).

Essas famílias passam por uma leitura, a partir das políticas públicas, em que têm se ancorado em sua responsabilização e/ou inculpação pelas questões que apresenta e, nessa perspectiva, essa responsabilidade familiar se institui na ideia em que

[...] para ser considerada uma boa família, ela deve ser capaz de prover financeiramente;

estabelecer vínculos afetivos positivos sem violência doméstica; manter as crianças na escola; cuidar de sua higiene, alimentação e vestuário; e conviver com parentes consanguíneos, como, por exemplo, avós e tios (CARLOTO; MARIANO, 2010, p. 457).

Sob esse viés da responsabilização da família como a principal encarregada pelos seus membros, ancorados na discussão da negligência apontada anteriormente, questionamos a responsabilidade do Estado e sociedade quanto a essa mesma família que sofre punição pelo acolhimento de suas crianças e/ou adolescentes quando vistas como negligentes. Mas afinal, o que é negligência? Segundo Minayo (2001), as negligências

[...] representam uma omissão em relação às obrigações da família e da sociedade de proverem as necessidades físicas e emocionais de uma criança. Expressam-se na falta de alimentos, de vestimenta, de cuidados escolares e com a saúde, quando as falhas não são o resultado

de

\footnotetext{
9 "A questão social diz respeito ao conjunto das expressões das desigualdades sociais engendradas na sociedade capitalista madura, impensáveis sem intermediação do Estado (IAMAMOTO, 2001, p. 16).
}

circunstâncias fora do controle e alcance dos responsáveis pelos adolescentes e crianças. Trata-se de um tipo de ação difícil de ser quantificado e qualificado, sobretudo quando as famílias estão em situação de miséria (MINAYO, 2001, p. 97-98).

Nesse sentido, "pode-se dizer que para que exista a condição de negligente é preciso que exista antes um modelo de proteção. Existindo esse modelo, qualquer desvio a ele é negligência" (NASCIMENTO, 2012, p. 41). Da falta de precisão do conceito derivam os malentendidos, visto que não há consenso sobre o termo, acarretando, então, práticas discriminatórias daqueles que atuam com as famílias: "[...] o peso que os profissionais jogam entre 'boas' e 'más famílias', muitas vezes funciona como verdadeiro álibi para justificar as carências das próprias intervenções" (BIANCO apud MIOTO, 2012, p. 132). Lembra Nascimento (apud MATA; SILVEIRA; DESLANDES, 2017) que o Estatuto da Criança e do Adolescente (BRASIL, 1990) não explicita o significado de negligência, se localizando no cotidiano a construção do referido termo, o que dificulta a unidade de sua compreensão. Todavia, espera-se que a partida para sua compreensão seja de uma perspectiva crítica, por se tratar de um fenômeno multidimensional.

Assim, é preciso analisar o fenômeno da negligência juntamente com as condições sociais de vida dos pais. Portanto, concluem as autoras: "uma criança mal-alimentada porque os pais não conseguem obter dinheiro para o fazer adequadamente, o caso não será considerado negligência" (AZEVEDO; GUERRA, 1989, p. 41). Dessa forma é preciso ter muito cuidado e precisão técnico-analítica para não confundir negligência com a situação de pobreza das famílias ou ausência de condições materiais de subsistência. Elas podem e devem ser supridas no conjunto das políticas públicas sociais protetivas, visando ao não agravamento da situação de vulnerabilidade ao ponto de avançar para processos de violência e posterior ruptura dos vínculos familiares e comunitários, culminando com o Acolhimento Institucional de crianças e adolescentes, com argumento fundamentado do "melhor interesse da criança" 
e "necessidade de proteção integral" (Art. 100 do ECA). Assim, perseguir o caminho realizado pelas instituições, que deveriam legalmente proteger as crianças e adolescentes, ainda no que denominamos de fase protetiva-preventiva, é fundamental para avançarmos na melhoria e qualificação das ações públicas de intervenção social com as crianças e adolescentes. Os resultados a serem perseguidos nessa fase da pesquisa qualitativa seguem nessa direção.

A manutenção da criança ou adolescente dentro do convívio familiar apresenta, atualmente, maior nível de possibilidades frente à nova concepção de família, que muito se distancia da família nuclear composta por pai, mãe e filho/a(s) e abre espaço para novos arranjos que agregam também avós, tios e membros da comunidade. Haja vista que, quando uma criança nasce, é a família que "vai se responsabilizando pela transmissão de valores e conhecimentos e pela socialização da criança, tornando-se fundamental pelos laços afetivos para o processo de subjetivação dessa criança" (SCODELARIO, 2002, p. 95).

Sabe-se que as políticas sociais são formuladas e estruturadas a partir de indicadores da realidade social, buscando promover direitos e superação de situações, sendo necessárias, inclusive, quando "os vínculos familiares estão fragilizados ou rompidos, oferecendo atenção especializada e acompanhamento sistemático em programas de orientação, apoio e proteção no contexto social" (BRASIL, 2006a, p. 53).

Nesse sentido, o Plano Nacional de Promoção, Proteção e Defesa do Direito à Convivência Familiar e Comunitária (BRASIL, 2006a), entre outros, busca

[...] 1) prevenção à ruptura de vínculos, por meio do trabalho com famílias em situação de vulnerabilidade social e/ou com vínculos fragilizados; 2) fortalecimento dos vínculos, apoio e acompanhamento necessário às famílias das crianças e dos adolescentes abrigados para a mudança de práticas de violação e para a reconstrução das relações familiares; 3) acompanhamento das famílias das crianças e adolescentes, durante a fase de adaptação, no processo de reintegração familiar; 4) articulação permanente entre os serviços de Acolhimento Institucional e a Justiça da Infância e da Juventude, para o acompanhamento adequado de cada caso, evitando-se prolongamento desnecessário da permanência da criança e do adolescente na instituição [...] (BRASIL, 2006a, p. 72-73).

Sob esse contexto, espera-se a articulação de outras políticas que possam garantir a superação desse direito violado e a reorganização dessa família, com objetivo de fortalecer vínculos. No entanto, quando a situação passa a ser judicializada, e o acolhimento institucional é tomado como medida emergencial, sem antes inserir as famílias em programas e serviços das políticas públicas que visam ao fortalecimento de vínculos, dificulta-se a proteção social e rompimento de ciclos de violência. As proibições de visitações, além do acolhimento institucional, aumentam a distância da criança e do adolescente do seu vínculo afetivo já fragilizado com sua família.

Por fim, as ações judicializadas, visando ao melhor interesse da criança ou adolescente, conforme prevê o Estatuto da Criança e do Adolescente, têm sido usadas como argumento para desresponsabilizar o Estado brasileiro pela violência estrutural e institucional cometidas sistematicamente contra as famílias e as crianças e adolescentes, que têm sido as maiores vítimas dessas famílias, também violadas pela ausência e/ou precarização das condições sociais e econômicas provocadas pela estrutura desigual que insiste em dividir em dois mundos desiguais: aquele em que existem uma infância e adolescência protegidas, e aquele em que há uma infância e adolescência violadas (AZEVEDO; GUERRA, 1989). Para estas, resta o Estado, que revitimiza e condena ao afastamento da família crianças e adolescentes como resposta protetiva. Nesse caso a semelhança com a Doutrina da Situação Irregular não nos parece mera coincidência. 


\section{CONCLUSÃO}

A partir dos 32 processos analisados, percebeu-se que existe dificuldade em identificar as famílias como alvo das políticas públicas, tornando-se o trabalho social com elas ainda mais distante quando existe rompimento total de vínculos entre seus membros.

Para Custódio e Veronese (2009, p. 141), o Sistema de Garantia de Direitos é compreendido como um "[...] sistema lógico, organizado sob a perspectiva de redes com responsabilidades compartilhadas entre a família, sociedade e Estado [...]". Ainda segundo Custódio (2006), o Sistema de Garantia de Direitos consiste num importante instrumento transformador da realidade social de muitas crianças e adolescentes e, para isso, é imprescindível que haja tomada de consciência e a prática de novas experiências emancipatórias, em detrimento daquelas de caráter repressivo-punitivo.

[...] o que implica repensar

toda a lógica socioassistencial e protetiva para a infância e repensar o papel das políticas sociais e, por fim, prevê que haja uma integração operacional do sistema, mais precisamente sob a perspectiva do trabalho em "rede" e de cooperações múltiplas entre os vários atores sociais pertencentes ao sistema de garantia de direitos (LIMA; VERONESE, 2012, p. 117).

O Conselho Tutelar, ao se colocar na posição de órgão de justiça sem a devida compatibilidade, dá entrada na revitimização de crianças e adolescentes que sofreram violação de direitos intrafamiliar. Dessa forma, o órgão não jurisdicional reverte seu papel de proteção para com o segmento, reforçado pela desarticulação com a rede socioassistencial.

A conceituação envolta na negligência, além de variada, é complexa. Precisa de aprofundamento, substancialmente para que se tenha um entendimento páreo entre todos os envolvidos, pois daí provêm práticas que impactam negativamente o indivíduo inculpado e responsabilizado pela negligência - para aqueles defensores da Doutrina da Proteção Integral, na qual nos incluímos, conveniente sinônimo de desproteção social. A pobreza se confunde com a negligência, tornando-se um motivo de acolhimento institucional disfarçado e gerando a criminalização da pobreza.

Conclui-se que o direito à convivência familiar e comunitária, apesar de caucionado pelo $E C A$, não é totalmente cumprido - influência provavelmente herdada do histórico punitivo das instituições totais de acolhimento - dado que algumas decisões judiciais não permitem a continuidade dos vínculos com a família, por meio da proibição de visitas. Outrossim, dificilmente, na judicialização dos direitos violados, os critérios de brevidade e excepcionalidade, dispostos na Lei 12.010 , são respeitados.

\section{AGRADECIMENTOS}

Ao Ministério Público de Santa Catarina (MPSC).

Aos estudantes e profissionais voluntários no auxilio técnico da coleta de dados, construção e organização do banco de dados.

$\mathrm{O}$ presente trabalho foi realizado com o apoio do Conselho Nacional de Desenvolvimento Científico e Tecnológico - CNPq - Brasil.

\section{REFERÊNCIAS}

AMORIM, D. C. A Doutrina de Proteção Integral de crianças e adolescentes nas políticas sociais: a realidade de Chapecó. 2017. Tese (Doutorado em Serviço Social) - Curso de Serviço Social, Universidade Federal de Santa Catarina, Florianópolis, 2017.

AZEVEDO, M. A.; GUERRA, V. N. A. (org.). Crianças vitimizadas: a síndrome do pequeno poder. São Paulo: Iglu, 1989.

BAPTISTA, M. V. O acolhimento excepcional e a responsabilidade da autoridade judiciária. In: CURY, M. (coord.). Estatuto da Criança e do Adolescente comentado: comentários jurídicos e social. 10. ed. São Paulo: Malheiros, 2010.

BARDIN, L. Análise de conteúdo. São Paulo: Edições 70; Martins Fontes, 1977. 
BRASIL. Ministério da Mulher, da Família e dos Direitos Humanos. Balanço Geral Nacional de Denúncias Disque 100. Crianças e Adolescentes. Período 2011 a 2019. Brasília, DF: 2020. Disponível em: https://www.gov.br/mdh/ptbr/acesso-a-informacao/ouvidoria/balancodisque-100. Acesso em: 18 set. 2020.

BRASIL. Constituição Federal (1988). Constituição da República Federativa do Brasil. Brasília: Senado Federal, 1988.

BRASIL. Ministério da Mulher, da Família e dos Direitos Humanos. Guia de Orientação do Processo de Escolha de Conselheiros Tutelares em data Unificada, Conselho Tutelar - Guia de Orientação do processo de Escolha. Brasília, 2019.

BRASIL. Lei 6.697 de 10 de outubro de 1979. Institui o Código de Menores. Diário Oficial da União, Brasília, 11 out. 1979.

BRASIL. Lei 8.069, de 13 de julho de 1990. Dispõe sobre o Estatuto da Criança e do Adolescente e dá outras providências. Diário Oficial da União, Brasília, 16 jul. 1990.

BRASIL. Lei 12.010, de 3 de agosto de 2009. Dispõe sobre adoção; altera as Leis nos 8.069, de 13 de julho de 1990 - Estatuto da Criança e do Adolescente, 8.560, de 29 de dezembro de 1992; revoga dispositivos da Lei no 10.406 , de 10 de janeiro de 2002 - Código Civil, e da Consolidação das Leis do Trabalho - CLT, aprovada pelo Decreto-Lei no 5.452, de 1 o de maio de 1943; e dá outras providências. Diário Oficial da união, Brasília, DF, 4 ago. 2009.

BRASIL. Plano Nacional de Promoção, Proteção e Defesa do Direito de Crianças e

Adolescentes à Convivência Familiar e Comunitária. Brasília: SEDH/CONANDA, 2006a.

BRASIL. Ministério do Desenvolvimento Social e Combate à Fome. Secretaria Nacional de Assistência Social. Política Nacional de Assistência Social (PNAS). Brasília: MDS, 2005.

BRASIL. Resolução 113 de 19 de abril de 2006. Conselho Nacional dos Direitos da Criança e do Adolescente (CONANDA). Dispõe sobre os parâmetros para a institucionalização e fortalecimento do Sistema de Garantia dos
Direitos da Criança e do Adolescente. Diário Oficial da União, Brasília: SEDH/CONANDA, 2006b.

BRASIL. Ministério de Desenvolvimento Social e Combate à Fome. Norma Operacional Básica de Recursos Humanos do SUAS (NOB/SUAS). Brasília: MDS, 2008.

CARLOTO, C. M; MARIANO, S. M. No meio do caminho entre o privado e o público: um debate sobre o papel da mulher na política de assistência social. Estudos Feministas, Florianópolis, p. 451471, maio/ago. 2010. https://doi.org/10.1590/S0104026X2010000200009

COSTA, A. A Violação de Direitos e o Sistema de Garantia de Direitos: olhares e percepções das crianças e adolescentes. 2020. Trabalho de Conclusão de Curso (Graduação em Serviço Social) - Curso de Serviço Social, Universidade Federal de Santa Catarina, Florianópolis, 2020.

COSTA, A. C. G. De menor a cidadão: notas para uma história do novo direito da infância e juventude no Brasil. Brasília: Ministério da Ação Social, 1995.

CUSTÓDIO, A. V. A exploração do trabalho infantil doméstico no Brasil contemporâneo: limites e perspectivas para a sua erradicação. 2006. Tese (Doutorado em Direito) - Programa de Pós-Graduação em Direito, Universidade Federal de Santa Catarina, Florianópolis, 2006.

CUSTÓDIO, A. V.; VERONESE, J. R. P. Crianças esquecidas: o trabalho infantil doméstico no Brasil. Curitiba: Multidéia, 2009.

DEMO, P. Metodologia científica em ciências sociais. 3. ed. São Paulo: Atlas, 1981.

DEMO, P. Pesquisa e construção do conhecimento: metodologia científica no caminho de Habermans. Rio de Janeiro: Tempo Brasileiro, 2000.

DEMO, P. Pesquisa e informação qualitativa. Campinas: Papirus, 2001.

DIGIÁCOMO, M. J. O Sistema de Garantias de Direitos da Criança e do Adolescente e o desafio do trabalho em "Rede". 2013. Disponível em: 
http://www.crianca.mppr.mp.br/arquivos/File/co nselhos_direitos/Sistema_de_Garantias_ECA_na_ Escola_II.pdf. Acesso em: 14 out. 2019.

D'ORNELLAS, L. S. O Acolhimento Institucional no ECA: teoria e prática. 2017. Disponível em: https://leandrosd.jusbrasil.com.br/artigos/14154 7875/acolhimento-institucional-no-eca. Acesso em: 07 ago. 2021.

FALEIROS, V. P. Infância e processo político no Brasil. In: PILOTTI, F.; RIZZINI, I. (org.). A Arte de Governar Crianças: A história das políticas sociais, de legislação e de assistência à infância no Brasil. 3. ed. São Paulo: Cortez, 2011.

FUCHS, A. M. S. L.; COPPINI, N. Relatório global de pesquisa: o Conselho Tutelar e a judicialização em casos de violação de direitos - um estudo dos encaminhamentos de Acolhimento Institucional ao Ministério Público de Florianópolis (SC). Florianópolis: UFSC/NECAD, 2021. (mimeo).

FERRARI, D. C. A.; VECINA, T. C. C. (org.). 0 fim do silêncio na violência familiar: teoria e prática. 4 . ed. São Paulo: Ágora, 2002.

IAMAMOTO, M. V. A Questão Social no Capitalismo. Temporalis, Brasília, v. 3, p. 9-32, 2001.

LIMA, F. S.; VERONESE, J. R. P. Os direitos da criança e do adolescente: a necessária efetivação dos direitos fundamentais. Florianópolis: Fundação Boiteux, 2012.

MATA, N. T.; SILVEIRA, L. M. B.; DESLANDES, S. F. Família e negligência: uma análise do conceito de negligência na infância. Ciência \& Saúde Coletiva, v. 22 , n. 9, p. 2881-2888, 2017. Disponível em: https://www.scielo.br/j/csc/a/pnr7XZk3BHd8dzw K3V3wQtd/?format=pdf\&lang=pt. Acesso em: 02 ago. 2021. https://doi.org/10.1590/141381232017229.13032017

MINAYO, M. C. S. Abordagem antropológica para avaliação de políticas sociais. Revista Saúde Pública, São Paulo, v. 25, 3. ed., 1991. https://doi.org/10.1590/S003489101991000300012

MINAYO, M. C. S. Violência contra crianças e adolescentes: questão social, questão de saúde. Rev. bras. saúde mater. infant.,, Recife, v. 1, n.
2, p. 91-102, maio/ago. 2001. https://doi.org/10.1590/S1519$\underline{38292001000200002}$

MIOTO, R. C. T. Processos de responsabilização das famílias no contexto dos serviços públicos: notas introdutórias. In: SARMENTO, H. B. M. Serviço Social: Questões Contemporâneas. Florianópolis: Ed. UFSC, 2012. p. 125-136.

NASCIMENTO, M. L. Abrigo, pobreza e negligência: percursos de judicialização. Psicologia \& Sociedade, v. 24 (n. spe.), p. 39-44, $2012 . \quad$ Disponível em: https://www.scielo.br/j/psoc/a/Cj3wKXhg7xYxht gFjwcLzMf/?format=pdf\&lang=pt. Acesso em: 03 ago. 2021. https://doi.org/10.1590/S0102$\underline{71822012000400007}$

RIZZINI, I. A institucionalização de crianças no Brasil: percurso histórico e desafios do presente. Rio de Janeiro: PUC-Rio; São Paulo: Loyola, 2004.

RIZZINI, I. (coord.). Acolhendo Crianças e adolescentes: experiências de Promoção de Direito à Convivência Familiar e Comunitária no Brasil. São Paulo: Cortez; Brasília, DF: UNICEF; CIESPI; Rio de Janeiro: PUC-RIO, 2006.

RODRIGUES, J. A C.; PEREIRA, P.C. Serviço Social e Psicologia no Judiciário: a prática do trabalho com famílias. In: BERNARDI, D. C. F. et al. (org.) Infância, Juventude e Família na Justiça. Campinas, SP: Papel Social, 2012. p. 96-109.

SANTOS, A. C. R. $\mathbf{O}$ acolhimento institucional de crianças e adolescentes: protege ou viola?. 2011. Dissertação (Mestrado em Serviço Social) Curso de Serviço Social, Pontifícia Universidade Católica do Rio Grande do Sul. Porto Alegre, $2011 . \quad$ Disponível em: https://repositorio.pucrs.br/dspace/bitstream/10 923/5144/1/000436231-Texto\%2BCompleto0.pdf. Acesso em: 03 ago. 2021.

SCODELARIO, A. S. A família abusiva. In: FERRARI, D. C. A.; VECINA, T. C. C. (org.). $O$ fim do silêncio na violência familiar: teoria e prática. 4. ed. São Paulo: Ágora, 2002. p. 95-106.

VERONESE, J. R. P.; COSTA, M. M. M. Violência Doméstica: quando a vítima é a criança ou adolescente - uma leitura interdisciplinar. Florianópolis: OAB/SC, 2006. 